\title{
Modelo de gestão em biotério convencional de produção de Rattus norvegicus de instituição de ensino superior privada brasileira
}

\author{
Carlos Alberto da Cruz Júnior ${ }^{1}$ \\ RESUMO - Este artigo apresenta um modelo de gestão em biotério convencional \\ de produção de Rattus norvegicus de Instituição de Ensino Superior Privada \\ Brasileira, sob enfoque crítico, com o propósito de obter a qualidade total por meio \\ da padronização como ferramenta gerencial. \\ Palavras-chave: gestão, biotério convencional, produção, Rattus norvegicus, \\ Instituição de Ensino Superior Privada, padronização, qualidade total.
}

\section{Pattern of management in a conventional vivarium Ciências of Rattus norvegicus production of Brazilian private hight education institutions

\begin{abstract}
This paper presents a pattern of management in a conventional vivarium of Rattus norvegicus production of Brazilian Private High Education Institutions under a critical focus with the purpose of obteining a total quality through the standardization as an underlying management tool.
\end{abstract}

Key words: management, conventional vivarium, Rattus norvegicus, production, Private High Education Institution, standardization, total quality.

O modelo de gestão em biotério convencional de produção de Rattus norvegicus de Instituição de Ensino Superior (I.E.S.) privada brasileira caracterizase, pela busca da qualidade total através da padronização.

1 Médico Veterinário, especialista em ciências de animais de laboratório pela Universidade de Buenos Aires e responsável pelo BioCIEN- Biotérios Labocien. Correspondências devem ser encaminhadas para: carlos61090@uniceub.br 
Visando melhoria na educação através da sistematização do conhecimento, estabelece diretrizes básicas para fundamentar a programação e análise da produção de sistema teste Rattus norvegicus em I.E.S que trabalha com ensino, pesquisa e extensão no Brasil.

Em 1904, instalou-se no Rio de Janeiro no Instituto Soroterápico, atual Fundação Oswaldo Cruz, o primeiro biotério de produção Brasileiro. Com as transformações da área biomédica ocorreu a necessidade de melhoria nas instalações de produção devido à necessidade crescente de animais para ensino e pesquisa. O rato tornou-se devido às suas características um excelente sistema teste, sendo o animal de laboratório mais difundido. Com a crescente necessidade de fornecimento de animais, tornou-se fundamental a otimização da produção por unidade de área, sendo necessário à definição de padrões. O bem estar animal é fundamental para atingir alta produtividade. Os biotérios são áreas de produção com programação arquitetônica definida dentro dos limites da espécie que aloja, com sistematização das atividades desenvolvidas pelos recursos humanos e análise de dados gerados pelas variáveis presentes.

Este artigo é uma reflexão que reorganiza e coordena informações obtidas pelo autor nos últimos anos a oportunidade que teve de participar de diferentes investigações para compor uma figura integrada, mas composta por partes autônomas. Tal como um calidoscópio.

\section{Instituição de Ensino Superior (I.E.S.) privada brasileira}

Em sentido estrito e convencional, sistema de ensino superior refere-se a um agregado de entidades formais, porém, em uma formulação mais ampla, o sistema de ensino superior pode ser designado como sendo "todos aqueles que desenvolvem atividades de ensino pós-secundárias: fiscalizadores, organizadores, trabalhadores ou consumidores" (Clark, 1983).

Com exceção dos sistemas exclusivamente públicos dos países socialistas, os sistemas nacionais de ensino superior têm caráter misto ou dual: caracterizamse pela presença da iniciativa privada, ao lado da pública, no atendimento da demanda por ensino superior. Ou seja, pela existência de um setor privado.

Há diferentes tipos de setor privado. A literatura comparada sobre sistemas de ensino superior, em geral, tende a defini-los em função de duas variáveis:

1) a dimensão que o setor privado assume em cada sistema, isto é, qual setor é predominante, se o público ou o privado;

2) a origem pública ou privada de seu financiamento. 
As variações nacionais que existem entre os setores privados decorrem, basicamente, do modo pelo qual esses dois aspectos se articulam nos sistemas nacionais. Em última instância, da dinâmica dos setores públicos e privados em sua interação com o Estado (Lévy,1986; Geiger,1986).

No Brasil as estatísticas oficiais para o ano de 1994 mostram que as matrículas no setor privado representavam 58\% de um total de 1.661 .034 matrículas; os estabelecimentos privados, por sua vez, respondiam por 755 das 851 instituições de ensino superior do país (MEC/SEEC, 1994). Trata-se, portanto, do setor predominante no sistema de ensino superior brasileiro, tanto no que concerne ao número de matrículas, como ao número de estabelecimentos. Na realidade, essa posição majoritária do ensino privado no sistema evidencia-se desde meados dos anos 60, quando o setor, com maior intensidade e velocidade que o setor público, respondeu a duas demandas que se complementaram: a demanda da clientela estudantil por ensino superior e a demanda do mercado ocupacional por pessoas portadoras de diploma de nível superior. A emergência desse mercado favorável ao desenvolvimento do ensino superior vinculava-se a processos mais amplos de modernização da sociedade brasileira, entre os quais se destacam as ampliações do atendimento dos níveis educacionais anteriores ao universitário, a urbanização e a industrialização do país (Schwartzman, 1988). O setor público, nesse período, também cresceu, mas não se orientou necessariamente para o atendimento da demanda de massa.

No Brasil, um estabelecimento privado de ensino superior pode distinguirse de outro, sob vários aspectos formais: sua natureza institucional (universidade, centro universitário, federação de escolas, escolas integradas ou faculdade isolada); a personalidade jurídica de sua mantenedora (fundação, associação civil, sociedade civil de direito privado), se tem ou não fim lucrativo, sua definição como laica ou confessional e, se confessional, a religião à qual está vinculada. As instituições privadas também se distinguem em função de aspectos referentes à organização acadêmica e aos serviços educacionais que prestam, escopo dos cursos de graduação e sua vinculação as diferentes áreas do conhecimento, relação candidato vaga em cursos para uma mesma formação, existência de pesquisa e pós-graduação, titulação do corpo decente, entre outros (Geiger, 1986).

Arrola-se ainda outros critérios menos usuais: se os estabelecimentos particulares atuam de forma que monopolizem a oferta privada de cursos superiores em uma determinada região ou se disputam com outras instituições privadas o atendimento da demanda, ou seja, se estão localizados em pequenos ou grandes centros urbanos. As instituições também apresentam diferenças marcantes em relação à variação do valor das anuidades cobradas dos alunos por cursos formalmente iguais (Geiger, 1986). 
De modo geral, sob todos esses aspectos, relevam-se as diferenças que existem entre os estabelecimentos privados no sistema nacional. Entretanto, se os agruparmos, verifica-se que essas diferenças remetem ao modo como essas instituições se relacionam com o mercado e com o estado (Geiger, 1986).

A relação do ensino privado com o mercado refere-se, em um primeiro nível, a capacidade do setor de suprir, mobilizando recursos privados, a demanda de massa por ensino superior. Dessa perspectiva, o mercado, entendido na equação oferta/ demanda, é determinante na ocorrência dos grandes movimentos de expansão e estagnação que se verificam na trajetória do setor privado no País nos últimos trinta anos. Sob esse aspecto, a relação do setor privado com o mercado é parte da dinâmica público/privado que logrou instalar-se ao longo do desenvolvimento do ensino superior brasileiro (Clark, 1983).

A relação do ensino privado com o mercado implica a atribuições de conteúdos específicos a oferta de formação de ensino superior. Não existe nem uma demanda genérica por ensino superior nem oferta indiferenciada de serviços nessa área. Como efeito, os estabelecimentos desenvolvem estratégias que motiva o próprio em sua relação com o mercado (Clark, 1983).

No que se refere à relação do setor privado com o Estado, é também necessário separá-lo em dois níveis. Em um primeiro nível, Estado refere-se à moldura legal que confere uma coesão formal ao sistema nacional de ensino superior. Nesse sentido, o Estado significa o conjunto de normas e leis específicas que regulamentam o desenvolvimento do sistema e fiscalizam o seu funcionamento. Essa dimensão corresponde a uma concepção fechada de sistema, como um conjunto de instituições de ensino superior sob o aparato legal de um estado nacional (Clark, 1983).

Todavia, a interação do setor privado com o estado não se restringe ao cumprimento de normas formais e ou ao encaminhamento de pleitos singulares para a apreciação e aprovação dos órgãos de controle. Embora o estado detenha o poder coercitivo e continuado do controle do sistema, são os governos que formulam e implementam as políticas para o ensino superior. Nesse sentido, a interação do setor privado com o Governo Federal manifesta-se no processo de negociação em torno dessa política, em especial das dirigidas as instituições privadas. Desse processo, participam as diferentes associações de representantes de interesses dos setores público e privado, bem como atores individuais em nome de suas instituições. As políticas voltadas para o ensino superior ganham, efetivamente, forma no decorrer do extenso processo de negociação que envolve diferentes atores do sistema. Essas negociações, freqüentemente, ocorrem de forma implícita e não tem visibilidade pública. Os atores se reconhecem em suas referentes posições e a negociação ocorre em uma arena oculta, na qual os sistemas 
organizados, o próprio sistema, exercem pressão em sentidos, na maioria das vezes, opostos, ainda que, freqüentemente, tendam a vocalização em nome de maior equidade e qualidade do ensino superior do Brasil. Esse processo permeia diversas arenas decisórias, as oficiais, as publicas e até as ocultas (Sampaio, 2000).

\section{Caracterização geral de biotérios}

Qualificar e quantificar as necessidades bem como o tipo de utilização que se vai levar a efeito, em instalações de Biotério, é uma tarefa complexa. Com efeito, os protocolos experimentais desenvolvidos em I.E.S. privadas apresentam elevado grau de variabilidade em função de diversos fatores, desde os interesses dos próprios docentes até a alocação dos recursos financeiros, o que dificulta a caracterização da demanda por animais de laboratório.

Por outro lado, as tarefas relativas ao planejamento e à programação de instalações para biotérios carecem, de dados e ferramentas suscetíveis de serem transformadas em informações para tomada de decisão em projeto. Esta situação leva muitas vezes à improvisação e a soluções não adequada, tendo em vista o elevado grau de confiabilidade sanitária e de padronização genética que os animais de laboratório devem apresentar.

A finalidade dessa subseção é identificar aspectos fundamentais que conduzam, com relativa segurança, à elaboração do projeto arquitetônico de forma a se explicitarem, coerente e sistematicamente, critérios programáticos e de avaliação, relativos a propostas de organização espacial de biotérios de produção em I.E.S. privadas.

Para as finalidades de programação arquitetônica de biotérios, considerase estes como sendo instalações capazes de produzir e manter o Rattus norvegicus destinado a servir como sistema teste rato em experimentos controlados, para atender às necessidades de ensino, pesquisa e extensão. Na medida em que as atividades evoluem de forma imprevisível, é necessário que, na fase de planejamento e construção, se estudem soluções flexíveis e adaptáveis às mudanças de exigências, nomeadamente quanto à sua expansibilidade modular.

O crescimento das instalações deve ser viabilizado sem solução de continuidade das atividades de criação em curso. Impõe-se uma estratégia de programação que incorpore, na fase de projetação e construção, esta desejada flexibilidade perante a incógnita do que serão os futuros protocolos experimentais.

Nas I.E.S. privadas os usuários de animais de laboratório apresentam interesses que vão desde pesquisas básicas até aulas demonstrativas de cirurgia, farmacologia, fisiologia, imunologia, hematologia para alunos dos cursos de graduação e pós- 
graduação. Os requisitos, neste caso, são amplos e diversificados. Verifica-se o uso irregular da variedade de linhagens e quantidades de animais utilizados não só em função dos cursos, mas também em função do calendário acadêmico ter ritmo (semanal, mensal, semestral ou anual) não homogêneo.

Estas variações no padrão de uso têm uma relação direta com a previsão de tendências, mais estáveis em curto prazo no ensino. No estudo, a não confiabilidade nos animais de laboratório pode trazer conseqüências indesejáveis como seja o atraso na realização de teses de pós-graduação ou a repetição de experimentos na graduação, dentro dos limites previstos na lista de ofertas de disciplinas, por sua vez condicionados ao calendário acadêmico da instituição. Tanto para o ensino quanto para a pesquisa, os animais devem ser hígidos. Somente onde características especiais de ensino ou pesquisa são requeridas, seria próprio utilizar animais dotados de caracteres incomuns.

$\mathrm{O}$ arquiteto que estiver encarregado de projetar o biotério não deverá esquecer que cada situação é específica, devendo esta ser definida em função do plano de produção elaborado pela comissão de especialistas da I.E.S. Recomenda-se que o levantamento prévio, para se conhecer a demanda e sua interpretação e avaliação, seja analisada por profissional experiente em ciências de animais de laboratório, que seja capaz de detectar as reais necessidades institucionais, corrigir as falhas, e ainda fazer previsões no aumento da demanda futura.

A programação de espaços para animais, em arquitetura, é registrada no mais antigo tratado de arquitetura. Como efeito, Vintruvio nos seus "Dez Livros de Arquitetura", já fazia referência aos conhecimentos que o homem pode obter através de animais quando descreve como "indicadores de zonas perigosas para a vida do homem".

O texto desse autor latino foi fonte de inspiração para toda a arquitetura clássica, especialmente no que se refere ao uso de analogias biológicas para descrever e normatizar o processo de projeção. Mesmo no século XX é Lê Corbusier que compara as virtudes da planta livre com a paralisada, como sendo a existente entre o sistema ósseo e a musculatura, observando que esta é flexível para agir e aquela rígida para fazer de suporte.

Apesar de ambas as concepções estarem sempre presente à analogia biológica o conhecimento ainda é renascentista, isto é, a ciência é entendida como sendo a resultante de aplicação de um método lógico subsidiado por uma erudição universal.

O espaço da experimentação somente começa a existir com o advento da ciência moderna e, no que se refere às preocupações espaciais que esta nova demanda gera por áreas de pesquisa com animais, é somente no pós-guerra que, em alguns países desenvolvidos, se começa a normalizar sobre esta temática. 


\section{Relação animal-ambiente artificial}

Como propõe Price (1976), é impossível ao homem reconstruir o ambiente natural das demais espécies animais, embora muitas espécies apresentem extrema tolerância para a adaptação às condições artificiais de cativeiro. Diz-se então, quando uma espécie atinge certa "estabilidade de adaptação", que está domesticada. A domesticação de animais torna-se um processo extremamente complexo à medida que se tem maior controle das condições ambientais artificiais, podendo ser acompanhada, ou não, de mudanças genéticas importantes, provocadas principalmente por: procriação consangüínea ("inbreeding”); desvio genético ("genetic drift") ou seleção natural (seja por relaxamento da seleção natural; por seleção artificial e por seleção natural em cativeiro). Meio ambiente e espaços mal planejados podem levar as diferentes espécies animais a situações dramáticas, como a super aglomeração que leva à asfixia ou ao canibalismo. O ambiente artificial transtorna, por vezes, aspectos comportamentais essenciais, observa Price (1976), como nas espécies que praticam a territorialidade (definição de áreas vitais, onde o animal tem certo tipo de domínio), mantendo-se apartados ou adotando comportamento relacionado com as áreas, ou território, de determinado indivíduo ou grupo, mas que em cativeiro passam a estabelecer hierarquias sociais, pois os indivíduos menos fortes não têm como evitar os indivíduos dominantes. $\mathrm{O}$ animal nascido e criado em um habitat natural possui a liberdade de escolher o microhabitat que melhor adequa às suas necessidades; em cativeiro pode não satisfazer às necessidades da espécie, devendo-se ter consciência da experiência individual de cada animal, em termos das experiências das primeiras fases do crescimento, do relacionamento, da reprodução, bem como da interação com os seres humanos.

\section{Conceito de padronização}

Nos biotérios modernos do mundo a padronização é considerada a mais fundamental das ferramentas gerências. Na Qualidade Total a padronização é a base para a Rotina (Gerenciamento da Rotina do Trabalho Diário). No entanto, a experiência tem demonstrado que a situação brasileira no tocante à padronização não é boa: falta literatura e faltam educação e treinamento das pessoas que ocupam cargos de liderança. Nos raros biotérios que se consideram padronizados, este assunto tem sido relegado aos técnicos, quando de fato é um encargo essencialmente gerencial. As pessoas que ocupam cargos gerenciais precisam entender que a padronização é o caminho seguro para a produtividade e competitividade ao nível internacional, pois é uma das bases onde se assenta o moderno gerenciamento.

O ser humano convive com a padronização há milhares de anos e dela depende 


\section{Carlos Alberto Jr}

para sua sobrevivência mesmo que disto não tenha consciência. Imagine uma pequena tribo ou aldeia no passado: a alimentação básica era o peixe. Pescavase de alguma forma até que alguém testou uma rede feita de cipó e pegou uma quantidade maior de peixes com menor trabalho. Evidentemente que outros habitantes da aldeia, tendo em vista os resultados obtidos, passaram a utilizar a rede como método de pesca.

Estava assim padronizado o método de pescar com rede. Mais tarde alguém julgou que seria melhor utilizar fios de juta do que cipó para fazer a rede. Tentou e isto resultou numa maior quantidade de peixes com menor trabalho. Os outros imediatamente adotaram a idéia (padronizaram). Algumas observações são importantes para serem comentadas:

a) Ninguém era obrigado a padronizar o método da pesca; fizeram isto somente porque dava melhor resultado;

b) A padronização é meio. O objetivo é, conseguir melhores resultados;

c) O método padronizado não é fixo: ele pode e deve ser melhorado para a obtenção de melhores resultados. Se os resultados forem melhores os outros adotarão o método revisto;

d) Originalmente não havia a necessidade de se registrar o método padronizado.

A aldeia era pequena e todos aprendiam o novo método naturalmente. A memória da aldeia era a memória das pessoas. Hoje a sociedade é complexa e para garantir a padronização é necessário registrar de forma organizada (em papel ou memória de computador) e conduzir formalmente o treinamento no trabalho.

A padronização deve ser vista, desta mesma forma, como algo que trará melhoras em qualidade, custo, cumprimento de prazo, segurança, etc.

A vida do homem seria hoje muito difícil, talvez inviável, sem a padronização (pense nas próprias palavras que utilizamos, em roupas, calçados, tráfego em ruas e rodovias, tráfego aéreo, materiais de construção, energia, etc.).

Imagine um pequeno fabricante de vasos cerâmicos. Ele fabrica manualmente vaso por vaso, cada um de um tamanho e modelos diferentes. Se este fabricante adotar alguns modelos básicos de vaso e fabricar apenas estes modelos ele estará padronizando a fabricação de seus produtos. Não é difícil imaginar que os seus custos irão diminuir e a produtividade irá crescer. Antes de padronizar o procedimento de fabricação seria muito difícil para ele treinar um ajudante, pois somente vários anos de prática poderia fazer do principiante "um bom oficial". No entanto, após padronizar fica fácil treinar, pois uma vez que se tenha o projeto do vaso e os procedimentos de fabricação, o treinamento fica muito facilitado. Decorre disto que mais vasos serão fabricados a um custo reduzido e melhor 
qualidade. Este exemplo do vaso se repete dia a dia diante de nossos olhos e nem sempre conseguimos enxergar. Um biotério tem uma autoclave onde é feito o tratamento térmico de 20 tipos diferentes de peças de constituições distintas. Cada tipo de peça é tratado numa temperatura diferente. Padronizando-se as temperaturas de operação da autoclave em, por exemplo, quatro faixas, é possível adaptar cada tipo de peça a uma das faixas. O resultado é o aumento da produção, redução dos custos e melhoria da qualidade.

Nos biotérios, grande parte das causas de problemas é se ter nos vários turnos operários executando a mesma tarefa de forma diferente. Esta é uma das grandes causas dos problemas das instituições brasileiras. Padronizar é reunir as pessoas e discutir o procedimento até encontrar aquele que for melhor, treinar as pessoas e assegurar-se de que a execução está de acordo com o consenso. Desta forma o trabalho nos vários turnos estará padronizado.

A padronização de biotérios de produção é em sua grande parte "voluntária", as pessoas discutem aquilo que será padronizado, estabelecem o procedimento padrão e o cumprem. Sua alteração é possível e até incentivada como forma de melhorar os processos. No entanto, há muitos casos em que a padronização resulta em "obrigatoriedade" como, por exemplo, a espessura mínima das tubulações submetidas a vapor em alta pressão; condições de projeto arquitetônico das salas de maternidade e crescimento; condições de fabricação de ração e condições de fabricação de autoclaves.

A definição de padronização não se limita ao estabelecimento (consenso, redação e registro) do padrão, mas inclui também sua utilização (treinamento e verificação contínua da sua observação). A padronização só termina quando a execução do trabalho conforme o padrão estiver assegurada ou na cabeça do usuário. É importante que o gerenciador de Biotério de Instituição Privada Brasileira observe este conceito, pois há muitos que consideram que está padronizado porque tem uma estante cheia de papel.

Todo gerente gerencia sistemas. No contexto de GQT, sistema é sinônimo de processo. Como conseguir alinhar "hardware" (equipamentos, materiais, produtos, etc.), "software" (procedimentos, técnicas, etc.) e homem (habilidade, comportamento, motivação)? A resposta passará inevitavelmente pela padronização, da qual decorre a educação, o treinamento e a delegação. 


\section{Papel da padronização no gerenciamento}

Não é necessário, por exemplo, que um gerente de compras seja um "comprador excepcional". É necessário, no entanto, que ele saiba gerenciar um "sistema de compras", ou seja, um conjunto de pessoas comprando de acordo com procedimentos previamente estabelecidos. Este gerenciamento em biotérios de produção é conduzido pelo método do ciclo PDCA como mostra a Figura 01.

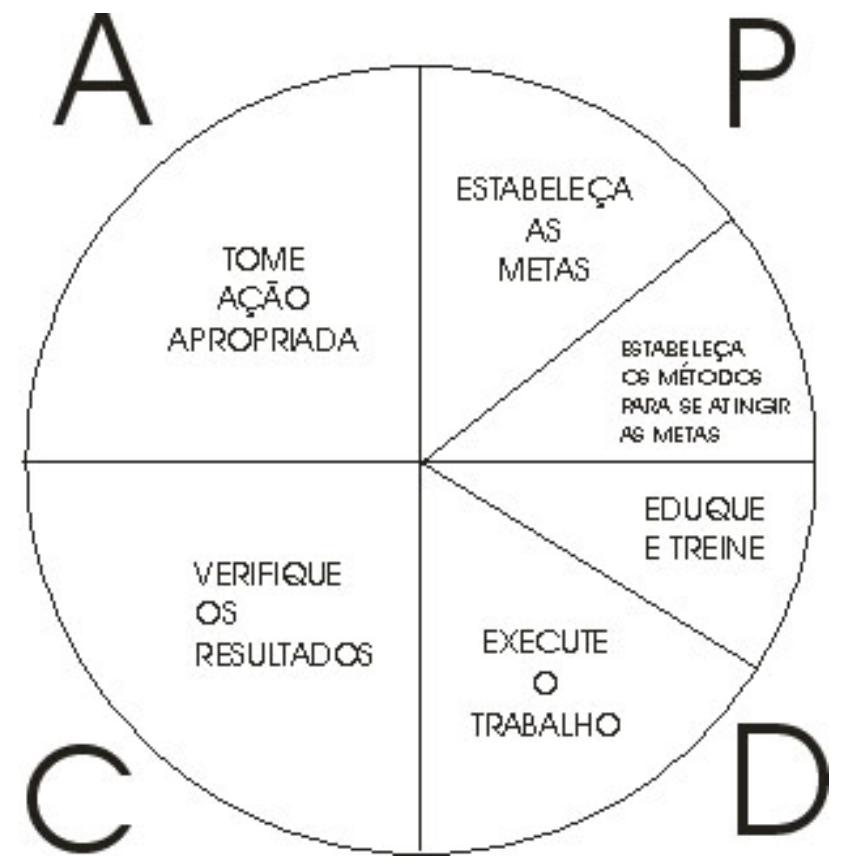

Figura 01 - Ciclo PDCA de Controle.

A utilização do método PDCA pode ser melhor compreendida verificandose a Figura 2. 


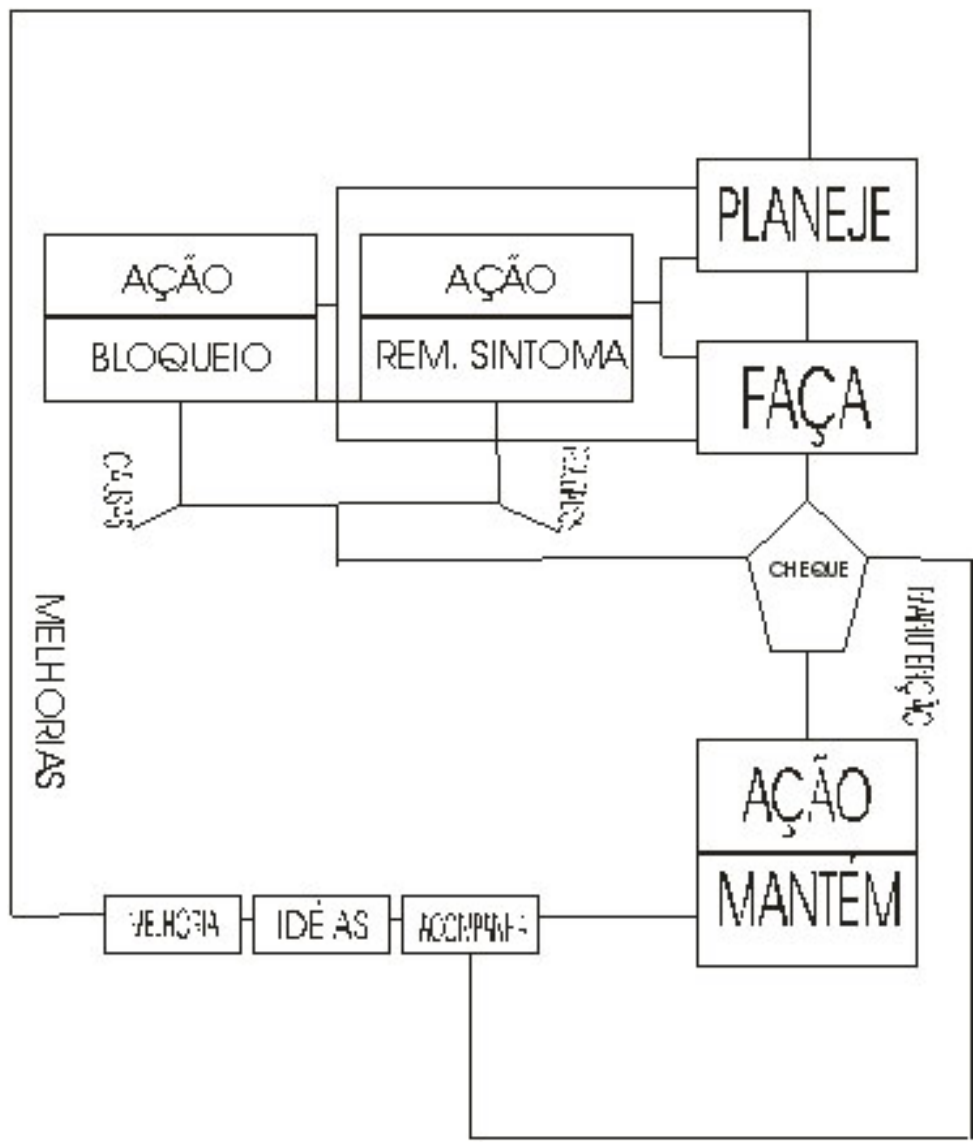

Figura 02 - Utilização do Método PDCA no Gerenciamento da Rotina.

Esta Figura representa a Rotina (ou Gerenciamento da Rotina do Trabalho Diário - "Daily Work Routine Management") e consta de:

(a) um ciclo de manutenção cujo objetivo é a previsibilidade dos resultados. Para isto, no ciclo de manutenção deve-se cumprir os padrões e atuar no resultado 
e nas causas dos desvios, quando indicado no procedimento operacional. Este papel é cumprido principalmente pelos operadores (exemplos de operadores: secretária, bioterista, comprador, pesquisador, professor, etc.).

(b) um ciclo de melhorias cujo objetivo é a competitividade do biotério, conseguida através da melhoria contínua dos resultados. As melhorias são conseguidas pela análise do processo e adoção de novo padrão (método de solução de problemas). Este papel é cumprido principalmente pelas chefias, staff (os operadores participam do ciclo das melhorias através dos círculos de controle da qualidade / CCQ) e supervisores.

O gerenciamento de processos repetitivos pelo ciclo PDCA é também chamado de "gerenciamento por sistemas". A abordagem por sistemas do controle da qualidade envolve estabelecer padrões de trabalho para cada etapa, desde o projeto até o produto final. Estes padrões incluem explicações de como verificar a existência de problemas (resultados desejados e não alcançados), como encontrar suas causas e como corrigi-las, de tal modo que os resultados desejados possam ser alcançados.

O gerenciamento por sistemas ou Rotina visa construir um processo sem problemas pela atuação metódica sobre a causa fundamental dos problemas, de tal maneira a aperfeiçoar constantemente o sistema. $\mathrm{O}$ gerenciamento por sistemas é a própria prática do controle da qualidade e, a padronização, tem uma importância fundamental no controle. Como o Gerenciamento pelas Diretrizes depende à rotina bem estabelecia. Decorre que a padronização é fundamental para todo o gerenciamento do biotério, tanto nas ações de rotina quanto do gerenciamento interfuncional.

Ter domínio tecnológico é: ser capaz de estabelecer sistemas (inclui especificar e projetar produtos e processos, "hardware e software"), assegurarse de que o que está sendo executado pelas pessoas corresponde ao que está registrado no sistema (treinamento no trabalho e auditoria); assegurar os objetivos de qualidade, custo, prazo, quantidade, local, moral e segurança (gerenciamento); ser capaz de analisar o sistema para garantir o atendimento das metas (controle de qualidade).

Isto parece óbvio, no entanto ao freqüentar biotérios brasileiros observamse disfunções reinantes principalmente pela inexistência do "domínio tecnológico". Só é possível manter o domínio tecnológico de um sistema através da padronização.

A consciência do conceito de "domínio tecnológico" deixa claro que os padrões são a base para o treinamento no trabalho. Sem a padronização fica difícil imaginar o treinamento funcional. 


\section{Significado do controle da qualidade}

Todo sistema tem uma missão. A missão do sistema é que o produto ou serviço dele decorrente tenha "qualidade total" ou "qualidade grande".Todo processo ou sistema deve garantir a qualidade total para o processo seguinte. Para que isto ocorra deve ser praticado o controle da qualidade. Praticar o controle de qualidade é eliminar a causa fundamental dos problemas do processo ou sistema (problema é qualquer resultado indesejável da qualidade total). A figura 03 mostra que praticamente o controle da qualidade significa que mediante a ocorrência de um desastre (problema, resultado indesejável) deve-se analisar o processo para descobrir a causa fundamental do problema (resultado indesejável), atuar na causa e observar o resultado; caso seja positiva, padronizar (adotar o novo procedimento) e estabelecer item de controle para vigiar a causa fundamental, para garantir que o resultado indesejável (problema) não retornará.

CONTROLE DA QUALImADE

PARA ELIMINAR AS CAUSAS

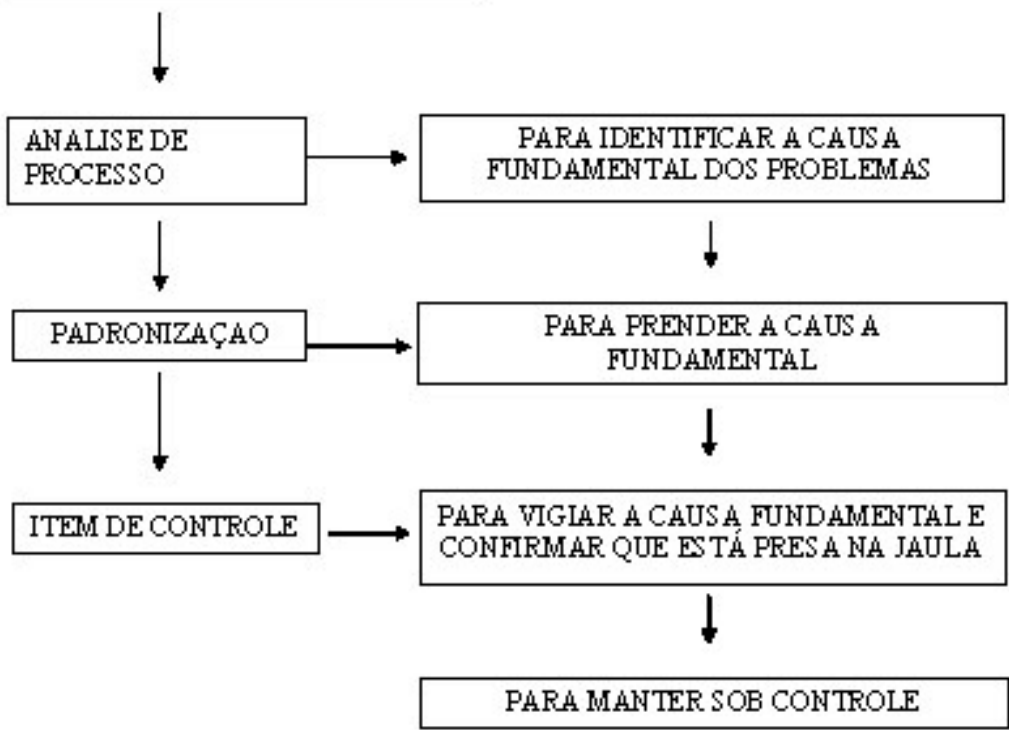

Figura 03 - Função da análise de processo, padronização e item de Controle de Qualidade. 
O controle de qualidade tem como objetivos, eliminar a causa fundamental dos problemas do tipo desvio de rotina ou dispersão (visando um processo cada vez mais previsível); eliminar as causas fundamentais dos problemas do tipo "melhoria de rotina" (visando um processo cada vez melhor).

A garantia da qualidade é atingida com a prática incessante do controle de qualidade. O controle de qualidade é praticado por todos através do "Gerenciamento da Rotina do Trabalho Diário".

\section{Métodos de padronização}

Jamais se estabelece um padrão sem que haja um objetivo definido (qualidade, custo, atendimento, moral e segurança) e a consciência de sua necessidade. Decidida a padronização as etapas básicas são (Miyauchi, 1987):
a) elaboração de fluxograma;
b) descrição do procedimento;
c) registro em formato padrão.

A Figura 04 mostra a seqüência geral da padronização, indicando as etapas básicas, a saber:

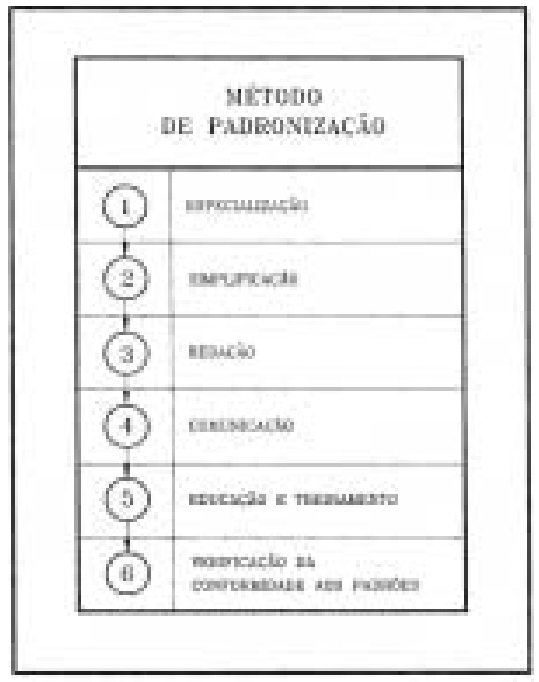

Figura 04 - Métodos de padronização. 
a) Especialização, escolher o sistema a ser padronizado determinando a sua repetibilidade. Por exemplo: o sistema de compras (que é repetitivo neste sistema, muito embora cada compra possa ser diferente); o sistema de desenvolvimento de novos produtos pode parecer inicialmente que não é repetitivo, pois a cada vez se desenvolve um produto diferente. Percebe-se que existe uma série de procedimentos básicos que são repetitivos e, portanto, padronizáveis. O mesmo se poderia dizer do planejamento, do gerenciamento pelas diretrizes, etc. Deve-se perguntar o que é repetitivo no sistema. Nesta etapa é importante estabelecer o fluxograma do processo repetitivo .

b) Simplificação: uma vez delimitada a repetibilidade e definido o sistema (processo), o próximo passo é a simplificação, que consta da redução do número de produtos, componentes, materiais e procedimentos e da simplificação do projeto dos produtos (visando reduzir custos);

c) Redação: redigir numa linguagem que as pessoas entendam, inclusive gíria e linguagem coloquial local;

d) Comunicação: comunicar com todas as outras pessoas ou departamentos afetados pelo padrão;

e) Educação e treinamento: o objetivo da padronização é conseguir com que as pessoas façam exatamente aquilo que tem que ser feito conforme determinação conjunta. $\mathrm{O}$ alvo principal é a mente das pessoas. O objetivo é fazer com que cada um seja "o mais competente em sua função";

f) Verificação da conformidade aos padrões: este é o principal papel de todas as chefias. $\mathrm{O}$ gerente supervisiona o sistema e o aperfeiçoa. $\mathrm{O}$ supervisor audita o trabalho do operador e o ensina. As metas da qualidade, custo, atendimento, moral e segurança devem ser alcançados.

\section{Características básicas dos padrões}

Os modelos de padronização poderão variar de biotério para biotério em função do tipo, tamanho e das condições locais. No entanto, alguns aspectos básicos devem ser observados:

a) Sempre que for redigido um padrão pergunte. Quem é o usuário? A padronização é conduzida para que os padrões sejam utilizados. Padrões expostos em arquivos não apresentam valor prático (Miyauchi, 1987). Sob este aspecto, existe muita incompreensão no Brasil. Pensa-se que o padrão é carregá-lo no bolso (costuma-se observar até padrões reduzidos e plastificados). Utilizar o padrão é gerenciar a rotina pelo método PDCA. Se o padrão não é alterado em seis meses é sinal de que não está sendo utilizado (Ishikawa, 1985).O controle não está sendo 


\section{Carlos Alberto Jr}

exercido.

b) Sempre que for redigido um padrão, pergunte: Este documento está na forma mais simples possível? O padrão deve ter o menor número de palavras possível e ser colocado em forma simples, sem prolixidade. Aqueles padrões de várias páginas que descrevem o trabalho de várias pessoas são de difícil acesso e utilização. No Brasil existem várias empresas que utilizam este formato de padrão.

c) O padrão pode ser cumprido? Padrões que não equivalem à situação atual são inúteis. Por exemplo: valores padrão podem ter sido especificados sem considerar as tolerâncias, ou as tolerâncias podem ter sido estabelecidas sem se considerar o nível tecnológico atingido pela empresa.

d) O padrão está suficientemente concreto? Padrões abstratos e de difícil entendimento também são inúteis. Por exemplo: simplesmente estipular que a "aparência e forma devem ser precisas e atraentes" não especifica o significado de "precisas e atraentes". Neste caso é necessário especificar concretamente o número máximo de arranhões permissível, ou o índice de reflexão da superfície, etc. Uma outra maneira é ter fotografias padrão representando o que é "preciso" e o que é "atraente".

e) Incorporação das Informações de vanguarda (Miyauchi, 1987). Todo conhecimento técnico da empresa deve fluir para os padrões como forma de serem utilizados pelos operadores para o benefício da comunidade.

f) Possíveis de serem revistos pelo menos uma vez por ano devido à incorporação de inovações (Miyauchi, 1987). O padrão é a base do PDCA e, portanto deve ser de fácil acesso e revisão.

g) Não se basear somente na teoria ou ser fruto de idealismos, porém ser solidamente baseado na prática (Miyauchi, 1987).

h) Deve ter a sua elaboração não restrita à delimitação da seqüência do trabalho, mas voltada ao atendimento das necessidades do trabalho. A própria redação deverá ser conforme o espírito de que o usuário é cliente do redator (Miyauchi, 1987).

i) Indicar claramente as datas de emissão e de revisão, o período da validade e as responsabilidades específicas (Miyauchi, 1987).

j) Os esboços deverão ser resultantes de um consenso, principalmente das áreas responsáveis (Miyauchi, 1987).

k) Os padrões devem ser autorizados por hierarquia imediatamente superior e cumpridos.

1) Um padrão, sendo parte de um sistema, nunca poderá contradizer outro.

m) Deverá ser mantido um controle da manutenção dos padrões e do número 
de revisões.

n) Os padrões devem ter seus nomes e formas padronizadas para toda empresa.

o) Os padrões devem direcionar-se para o faturo a partir de uma situação atual dominada.

\section{Formato dos padrões do biotério}

Os requisitos dos padrões são: fácil leitura, fácil para a revisão, fácil e conveniente para duplicar, fácil manuseio e poucos erros.

Os padrões devem ser feitos em folhas soltas (papel ou cartolina) que sejam convenientes de serem corrigidas, inseridas ou trocadas. O tamanho do papel utilizado é, geralmente, o A-4. Ao se duplicar um padrão tome como norma sempre utilizar o original como matriz. O padrão deve conter um número, o título, a data de estabelecimento do padrão ou a da última revisão.

A redação deve ser feita de tal maneira que o operador possa entender. Desta forma, uma linguagem coloquial e a colocação da idéia em forma de itens é permitida. Termos, números, símbolos de unidade, símbolos em letra, símbolos gráficos, sinais, figuras, tabelas, fotos, fórmulas, etc., devem ser definidos previamente, no próprio padrão ou no manual de treinamento, de tal forma a não criar dúvidas.

A numeração dos padrões deve ser feita dentro de um sistema de numeração metódico, previamente definido. Este sistema de numeração deve estar de acordo com o sistema de classificação de padrões.

\section{Procedimento operacional (standard operation procedure)}

O procedimento operacional é preparado para as pessoas diretamente ligadas a tarefa com o objetivo de atingir de forma eficiente e segura os requisitos da qualidade. Portanto, este documento será sempre o ponto final do fluxo das informações técnicas e gerenciais. Ele é feito para o operador e contém:

a) Listagem dos equipamentos, peças e materiais utilizados na tarefa, incluindo-se os instrumentos de medida;

b) Padrões da qualidade;

c) Descrição dos procedimentos da tarefa par atividades criticas, condições de produção e de operação e pontos proibidos em cada tarefa;

d) Pontos de controle (itens de controle e características da qualidade) e os métodos de controle; 
O procedimento operacional deve conter, da forma mais simples possível, todas as informações necessárias ao bom desempenho da tarefa.

A forma do procedimento operacional não é o fato importante. O importante é levar a cada executor todas as informações necessárias. No procedimento operacional é importante observar as atividades críticas que devem ser resumidas e conter somente aquelas etapas básicas que não podem deixar de ser feitas. As atividades criticas são detalhadas no manual de treinamento, no qual podem ser utilizadas figuras, fotos e esquemas. O manual de treinamento pode ainda ser colocado sob a forma de vídeo ou áudio visual para facilitar o treinamento. Também no manual de treinamento a forma não é o mais importante e sim o objetivo final de ter o executor qualificado.

Os procedimentos operacionais podem ser divididos em dois tipos:

a) Procedimentos operacionais gerais;

b) Procedimentos operacionais específicos.

Os procedimentos operacionais gerais são aqueles conduzidos constantemente pelo operador. Por exemplo: como operar uma balança, como lavar uma caixa, etc. O procedimento operacional específico é aquele levado ao operador para alguma operação especial. Por exemplo, o operador opera a balança seguindo o procedimento operacional geral. Entretanto, a idade do animal que está sendo pesado determinará a as dimensões da plataforma de contenção que utilizará. Neste caso usa-se um procedimento operacional especifico para aquela idade de animal.

A Qualidade Total é conduzida de tal forma a dar ao operador as melhores condições de trabalho que constam de: trabalho seguro, tranqüilo e onde o próprio operador possa gerenciar (manter e melhorar) sua área de trabalho. Para tanto são necessárias as seguintes precondições:

a) Ele deve estar familiarizado com o objetivo do seu trabalho;

b) Ele deve saber julgar a qualidade do seu trabalho (auto-inspeção);

c) Ele deve saber corrigir seu trabalho quando algo de anormal ocorrer (autocontrole), sempre que estas instruções específicas constarem do procedimento operacional.

É responsabilidade do supervisor informar ao operador os três itens anteriores que devem ser considerados durante a padronização. 


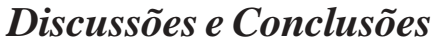

1) Padronização como meio de transmissão de informações: padronização viabiliza a transferência de tecnologia (que de outra forma só poderia ser feita de forma verbal); viabiliza a informação dos clientes através das especificações, catálogos de preços, etc.; viabiliza a transmissão de informações sobre os regulamentos internos do biotério; viabiliza a educação e treinamento como forma de se levar aos níveis inferiores da hierarquia as informações necessárias ao desempenho de suas funções; promove a melhoria da moral.

2) Registro da técnica do biotério: sistema de padronização permite registrar a técnica pessoal como técnica do biotério (e difundir esta técnica através da educação e treinamento).

3) Manutenção e melhoria da qualidade permite a melhoria da intercambialidade dimensional, funcional e de componentes; a mínima utilização de componentes; a melhoria e garantia da confiabilidade; a produção com qualidade uniforme; a eliminação de dificuldades e problemas de processamento; a prevenção da ocorrência de problemas; o estabelecimento de procedimentos padrão de operação.

4) Redução do custo: para melhoria da intercambiabilidade dimensional, funcional e de componentes; pela utilização mínima de componentes; pela simplificação.

5) Manutenção e melhoria da produtividade: por permitir o projeto e melhoria do processamento em produção de massa; por permitir melhorias no processo; por ser a base para a implantação de automação, por ser a base para a informatização.

6) Contribuição social: por permitir melhores condições de segurança no trabalho; por permitir o controle ambiental, por permitir a garantia da segurança aos clientes.

\section{Referências}

CLARCK, B. (1983). El sistema de educacion superior: una visión comparativa de la organización académica. México: Universidad Autonoma Metropolitana.

GEIGER, R. (1986). Private Sectors in Higher Education: Structure, Function and Change in Eight Countries. An Arbor: The University of Michigan Press.

ISHYKAWA, K. (1984). Quality and Standaridzation:Program for Economic Success, 
Quality Progress. [S.1.:s.n], p.16-20.

LÉVY, D. (1986). Higher Education and Stak in Latin America: Private Challenges to Public Dominance. Chicago: University of Chicago Press.

Ministério da Educação e Cultura/Instituto Nacional de Estudos e Pesquisas Educacionais. Sinopse estatística da educação superior-graduação (1984). Brasília: [s.n].

MIYAUCHI, I. (1987). Postura de um coordenador de TQC: "Total Quality Control: uma Aestratégia competitiva". In: Seminário Internacional de TQC. São Paulo, SP: [s.n].

PRICE, E.O. (1976). "The Laboratory Animal and its Enviroment": The Control of the Animal House Environment. Londres: T. Mc Sheery Laboratory Animales.

SAMPAIO, H. M. S. (2000). O Ensino Superior no Brasil: o setor privado. São Paulo, SP: Hucitec, 392p.

SCHWARTZMAN, S. (1988). Brasil:Opportunity and Crisis in Higher Education. [S.1.:s.n], p.99-119. 